\title{
Two Rare Cases of Bi-Abdomen and a Polar Gynandromorphism in Culicoides (Biting Midges) from Makurdi, Nigeria
}

\author{
1*Oke, P. O., ${ }^{2}$ Oke, B. E., ${ }^{3}$ Wanmi, N., ${ }^{3}$ Samuel, O. M. and ${ }^{4}$ Adejinmi, J. O.
}

\author{
${ }^{1}$ Department of Veterinary Parasitology \& Entomology, College of Veterinary Medicine, Federal University of Agriculture Makurdi, Benue \\ State Nigeria \\ ${ }^{2}$ Department of Theriogenology, College of Veterinary Medicine, Federal University of Agriculture Makurdi, Benue State \\ ${ }^{3}$ Department of Veterinary Anatomy, College of Veterinary Medicine, Federal University of Agriculture Makurdi, Benue State \\ ${ }^{4}$ Department of Veterinary Parasitology \& Entomology, Faculty of Veterinary Medicine, University of Ibadan, Oyo State Nigeria
}

*Author for Correspondence: dvmoke@yahoo.com

\begin{abstract}
Three developmental abnormalities were found out of a total sample of eight hundred and twenty two within the genus Culicoides. These are two rare cases of double abdomen in females of the Schultzei and Imicola groups and a polar gynandromorphism, all in the genus Culicoides (biting midges) from Makurdi, Benue State, Nigeria. These females show double symmetrical abdomens equally attached to the meta-thorax and are related both on dorsal and ventral relative positions as well as larger and smaller relative capacities. The bi-abdomens in the Culicoides oxystoma (Schultzei group) were also separated by a speculated third rudimentary abdomen similarly attached to the meta-thorax; both abdomens possess three spermathecae (receptacula seminis) each but two spermathecae in the Culicoides imicola (Imicola group). The dorsal abdomen possesses eleven spiracles while the ventral sac, ten in the Culicoides oxystoma and revealed evidence of functionality; the dorsal abdomen was observed filled while the ventral only shows a smaller content volume. Both bi-abdominal specimens demonstrated no other apparent morphological dysfunction of other parts. On the other hand, the polar gynandromorphic specimen on stereomicroscopy revealed a typical female anterior portion and a posterior portion characteristic of male adult Culicoides. Further examination of the specimen showed absence of spermatheca. These abnormalities are the first reports of any type in invertebrates in Nigeria.
\end{abstract}

Keywords: Culicoides; Developmental Abnormalities; Bi-Abdomen; Polar Gynandomorphism

\section{INTRODUCTION}

Several developmental anomalies in the class insecta have been reported in veterinary literature. Such anomalies affect several segments including the genitalia, antenna, wing and mouthparts and both sexes are equally predisposed. It is understood that developmental anomalies stems from genetic aberrations of disturbed embryologic pathways (Gilbert, 2008). The destruction of the RNA at the anterior portion of insects' egg by the enzyme RNAse and ultraviolet rays may result in several morphological anomalies and subsequent duplications of insect' body structures (KandlerSinger and Kalthoff, 1976).

Gynandromorphism is an unusual condition in which an individual possesses a morphological characteristic of female and male (Heming, 2003). It is a rare observable fact that has been reported in both vertebrates and invertebrates (Skvarla and Dowling, 2014; Sample, 2011; Williams, 2010, Bear and Monterio, 2013) and has been reported in thirteen insects' order and sixty-nine families (Cui and Cui, 2003). Four categories of gynandromorphism have been documented and these are: Polar, Bilateral, Oblique and Spiral. In polar gynandromorphism, the head/antenna (anterior) is made up of one sex while the abdomen/genitalia (posterior) of another sex. Gynandromorphism can be as a result of genetic complications possibly due to somatic crossing over, improper migration of chromosomes in early mitotic division (Seal,1966), binucleate eggs independently fertilized by male gametes (Ahmad et al., 1985) and two sperms fused with products of female meiosis in a single egg (Clements, 1992).

These abnormalities observed (double abdomens and polar gynandromorphism) to the best of our knowledge are the first report in this species in Nigeria.

\section{MATERIALS AND METHODS}

Nigeria, a West African country lies on $9^{\circ} 820^{\prime} 0.0000^{\prime \prime}, 8^{\circ}$ $6753^{\prime} 0.0000^{\prime \prime}$ co-ordinates of the equator. An entomological survey on 822 Culicoides species especially of the Schultzei group was carried out in two geographical 
locations (Table 1), with the aim to determine their distribution, prevalence and impact on disease transmission.

\section{RESULTS AND DISCUSSION}

During stereomicroscopic separation of Culicoides from non-Culicoides, an initial bi-abdominal specimen. Upon further search, a total of two cases of bi-abdomens and a polar gynandromorphism was discovered. The present cases
(Figure 1a and 1b) were encountered among specimens collected from Makurdi (Benue State).

A thorough examination of our specimen (gyander) revealed a distinct line of separation between the female and male parts and this differentiated it from intersex as reported by Reinhart (1966).

Table 1: Estimated species concentration distribution of trapped Culicoides (Schultzei group) in two locations in Nigeria (Ibadan and Makurdi)

\begin{tabular}{llll}
\hline Location & GPS Coordinates & Species & Prevalence (Counts assessed) \\
\hline Ibadan & $7.39638889 ; 3.91666667$ & C. oxystoma & $18.31 \%(93)$ \\
& & C. enderleini & $69.48 \%(353)$ \\
& C. schultzei & $5.71 \%(29)$ \\
Makurdi & $7.73055556 ; 8.53361111$ & C. subschultzei & $6.50 \%(33)=508$ \\
& & C. oxystoma & $17.83 \%(56)$ \\
& & C. enderleini & $34.08 \%(107)$ \\
& C. schultzei & $17.83 \%(56)$ \\
& C. subschultzei & $30.25 \%(95)=314$ \\
\hline
\end{tabular}

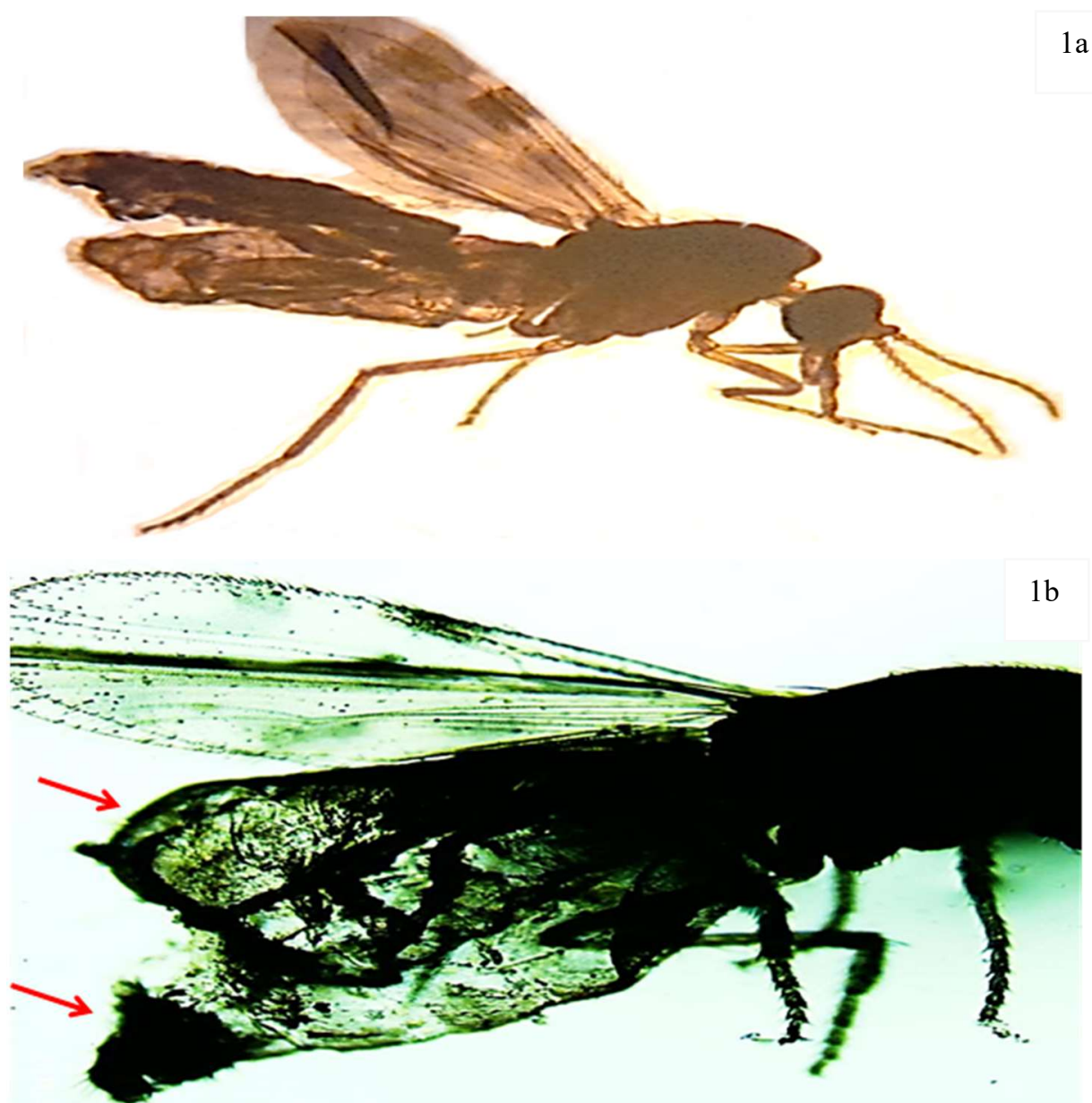

Figure 1a and 1b: Right lateral view of Culicoides oxystoma (1a) and C. imicola (1b) demonstrating bi-abdominal segments and a rudimentary third all attached to the metathorax.

The polar gynander showed a characteristic female anterior (the antenna, mouthparts, compound eyes and the wings) and a posterior portion typical of male (i.e. the abdomen and the genitalia) Culicoides species as reported by Wirth and
Hubert (1989). Our finding was in agreement with the observations made by Curtis (1962), Kamel (1965) who reported polar gynandromorphism in different species of Culicoides. There is paucity of information generally on gynandromorphism and the established fact that not a single 
incidence has been reported in Nigeria is an indication of it been a rare phenomenon (Williams 2010, Sample 2011, Skvaria and Dowling 2014).

In between the dorsal and ventral abdomens of the initially described specimen lies a suspected attenuated third abdomen (Figure 2b) similarly attached to the meta-thorax.
Both the dorsal and ventral abdominal structures revealed evidence of functionality due to presence of functional spermathecae (three each on the dorsal and ventral abdominal segments for the Culicoides oxystoma specimen (total six) and two functional spermathecae for the $C$ imicola sample.

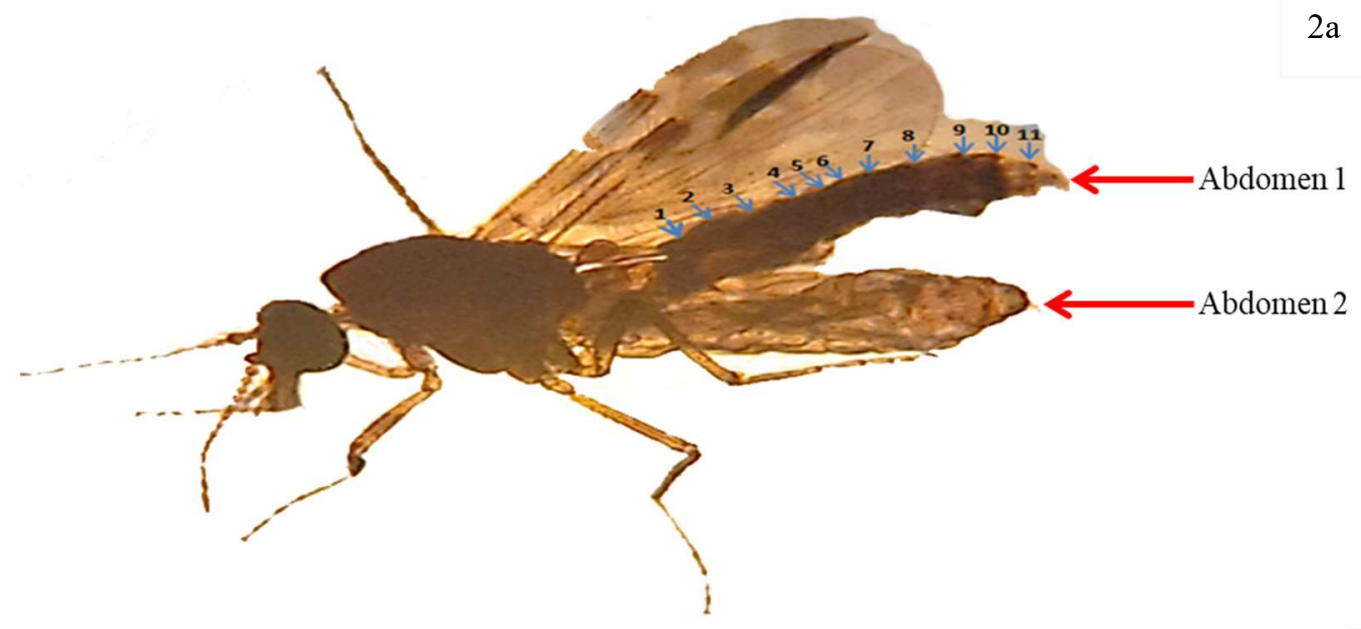

Abdomen 1

$2 b$

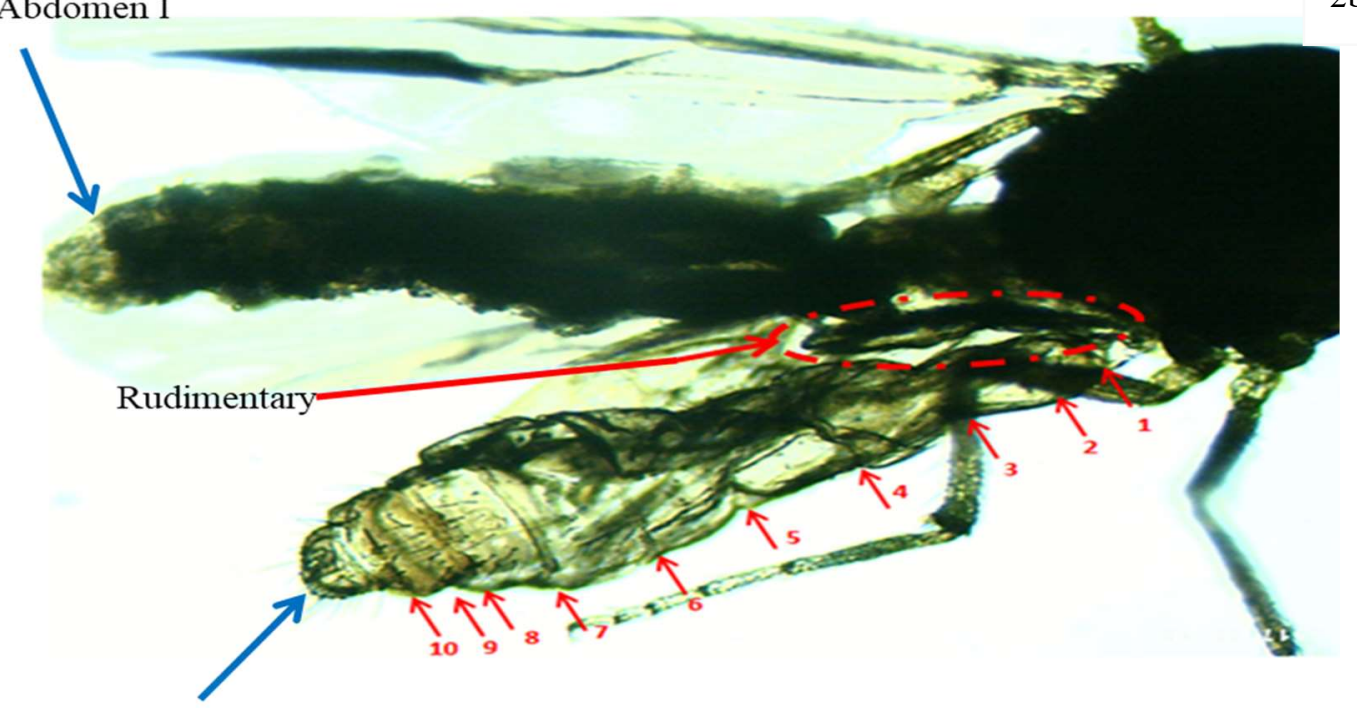

Abdomen 2

Figure 2a and 2b: Left and right views of Culicoides oxystoma showing (2a) Dorsal and ventral abdominal attachments, (2b) dorsal and ventral sac spiracles as well as the rudimentary structure (circled in red dashes) between both abdomens.

A comparison was made between the gynander and a typical male and female specimen of the same species reported by Oke et al. (2016 and 2017). It was observed that the gynander has combined characteristics typical of both male and female. Further examination of the abdomen on higher magnification indicated absence of spermathecae, a finding that equally confirmed a posterior male feature. This was in agreement with Curtis (1962) who also reported absence of spermathecae in gynander specimen.

The gynandromorph was identified morphologically as Culicoides subschultzei. The specimen showed a characteristic polar gynandromorphism (anterior-posterior). The head and the associated accessory structures together with the wings were typical of a female biting midge
(Figure 3: white arrow) whereas the posterior part was characteristic of a male biting midge with slender abdomen and conspicuous terminal male genitalia (Figure 3: black arrow). Despite that the gynandromorph had a typical female anterior; there was no evidence of previous blood feeding either through engorgement or presence of Burgundy pigment in the abdominal segment. A closer look at the specimen using higher magnification revealed absence of spermatheca and this further established a posterior male.

Despite the possession of typical female mouthparts, there was no evidence of engorgement with blood. However, there could be the possibility of alterations in the feeding habits but this could not be established since the gynander died after trapping. 
Generally, genetic mutations in insects alter individual segments and compartments into one another leaving other developmental co-ordinates unchanged (Garcia-Bellido, 1977). This condition has been suggested to be due to a maternal effect mutant bicoid gene (Frigerio et al., 1986).

Phenotypic anomalies in Culicoides though fairly reported in Veterinary entomologic literatures need to be further investigated with bias in molecular genetics, this might be key in viral disease epidemiology and control if indeed mutant alleles introduced are responsible for such teratologies. These conditions have however not been proved to be incompatible with life in insects.

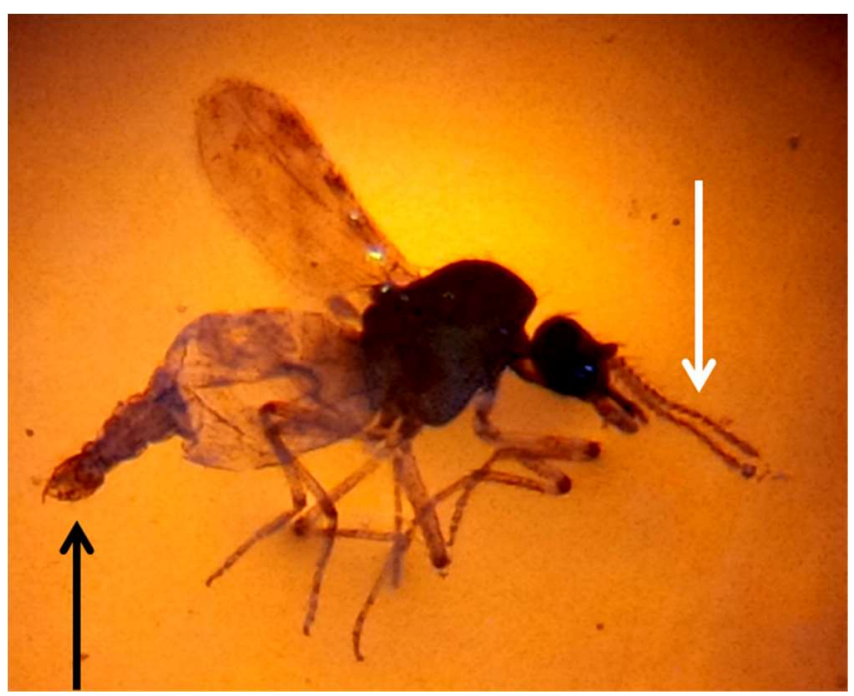

Figure 3: A polar gynandromorphism Culicoides subschultz ei showing characteristic female head (White arrow) and male genitalia (Black arrow)

The occurrence and frequency of such abnormalities in population samples especially during rainy seasons (between March and early November) (NIMET, 2010) seem to suggest environmental input on morphogenetic dynamics in this species embryo.

Among the species reported, Culicoides oxystoma has been established a proven vector in the transmission of bovine arboviruses such as Akabane in Japan (Kurogi et al., 1987; Yanase et al., 2005). It is a suspected vector of epizootic haemorrhagic disease virus in Israel (Morag et al., 2012 and a potential vector of the bluetongue virus (BTV) in India (Dadawala et al., 2012) while Culicoides enderleini is a potential vector for BTV in South Africa (Venter et al., 2006; Nevill et al., 1992)

\section{Conclusion}

These abnormalities (bi-abdomens and gynandromorphism) to the best our knowledge is the first to be reported in Nigeria in invertebrate.

\section{Conflict of Interest}

The authors declare that they do not have any conflict of interest.

\section{Authors Contribution}

OPO and AJO designed the study. OPO, OBE and WN collected samples. OBE, WN, SMO and AJO analyzed the data and interpreted the results. OPO and SMO drafted the manuscript. All authors have read and approved the final manuscript.

\section{REFERENCES}

Ahmad, W., Ara A., and Adhami, U.M. (1985). Genetic studies on gynandromorphism (sgm, gm) in Culex pipiens fatigans. Experientia (Basel) 41: 14651467.

Bear, A., and Monteiro, A. (2013). Both cell-autonomous mechanisms and hormones contribute to sexual development in vertebrates and insects. Bioessays $35,725-732$.

Clements, A.N. (1992). The biology of mosquitoes. Volume I: Development, nutrition, and reproduction. Chapman Hall, London. Pp 509.

Cui, J., and Cui, W. (2003). Gynandromorphism in insects. Entomological Knowledge 40(6), 565-570 (in Chinese with English summary).

Curtis, L.C. (1962). A gynandromorph in Culicoides. Mosquito News. 22(1):53.

Dadawala, A.I., Biswas, S.K., Rehman, W., Chand, K., De, A., and Mathapati, B.S. (2012). Isolation of bluetongue virus serotype 1 from Culicoides vector captured in livestock farms and sequence analysis of the viral genome segment-2. Transbound Emerg Dis. 59:361-8.

Frigerio, G., Burri, M., Bopp, D., Baumgatner, S., and Noll, M. (1986). Structure of the segmentation gene paired and the Drosophilia PRD Gene Set as part of a gene Network, Cell. 47: 735-746

Garcia-Bellido, A. (1977). Homoeotic and atavic mutations in insects, Amer. Zool., 17:613-629

Gilbert, F. (2008). Developmental Biology, 8th edn Sunderland, MA: Sinauer, pp. 220-233

Heming, B.S. (2003). Insect development and evolution. Cornell University Press, Ithaca and London, 444p.

Kamel, T.K. (1965). Gynandromorphism in Culicoides hollensis. Mosquito News, 25 (4):484-485

Kandler-Singer, I., and Kalthoff, K. (1976). RNase sensitivity of an anteriormorphogenetic determinant in an insect egg (Smittia sp., Chironomidae, Diptera) Proc Natl Acad Sci U S A. 73(10):3739-43.

Konopova, B., and Akam, M. (2014). The Hox genes Ultrabithorax and abdominal-A specify three different types of abdominal appendage in the springtail Orchesellacincta (Collembola), EvoDevo, $5 ; 2$

Kurogi, H., Akiba, K., Inaba, Y., and Matumoto, M. (1987). Isolation of Akabane virus from the biting midge Culicoides oxystoma in Japan. Vet Microbiol,15(3):243-8.

Morag, N., Saroya, Y., Bravermann, Y., Klement, E., and Gottlieb, Y. (2012). Molecular identification, phylogenetic status and geographic distribution of 
Culicoides oxystoma (Diptera: Ceratopogonidae) in Israel. PLoS ONE. 7(3): e33610.

Nevill, E.M., Venter, G.J., and Edwardes, M. (1992). Potential Culicoides vectors of livestock orbiviruses. In: Walton TE, Osburn BI, editors. Bluetongue, African horse sickness, and related orbiviruses: Proceedings of the 2nd International Symposium. Boca Raton, Florida: CRC Press. P. 306-13.

Nigerian Meteorological Agency (NIMET). (2010). Nigeria climate review bulletin, $10 ; 15-20$

Oke, P.O., Adejinmi, J.O., and Oke-Egbodo, B.E. (2016). First Record of Culicoides oxystoma, and other three members of the Schultzei group in Nig. $J$. Agric. Vet Sci. 9, (2):51-56

Oke, P.O., Oke, B.E., and Adejinmi, J.O. (2017). Swine farm infestation with Culicoides species (biting midges) in Zaria, Nigeria. Sokoto $J$. Vet. Sci., 15(2): 66-69.

Reinert, J.F. (2000). Assignment of two American Species of Aedes to Subgenus Rusticoidus, J. Am. Mosq. Cont. Assoc., 16(1):42-43

Reinhart, B. (1966). Gynandromorphs and intersexes in Mosquitoes (Diptera: Culicidae Can J.Zool.,44: 911-921

Sample, I. (2011). Half male, half female butterfly steals the show at Natural History Museum. The Guardian (Available from http://www.theguardian. com/science/2011/jul/12/half-male-half-femalebutterfly/ April 2016).
Seal, C.W. (1966). A gynandromorph of Culex pipiens quinquefasciatus (Say). Mosquito News, 26, 586589.

Skvarla, M.J., and Dowling, A.P.G. (2014). First report of gynandromorphism in Temnothorax curvispinosus (Mayr, 1866) (Hymenoptera: Formicidae). Proc. Entomol. Soc. Wash. 116(3), 349-353.

Venter, G.J., Mellor, P.S., and Paweska, J.T. (2006). Oral susceptibility of South African stock associated Culicoides species to bluetongue virus. Med Vet Entomol, 20: 329-34.

Williams, H. (2010). Half-cock chicken mystery solved. BBC News (Available from http://news. bbc.co.uk/2/hi/uk_news/scotland/edinburgh_and_ east/8561814.stm/April 2016).

Wirth, W.W., and Hubert, A.A. (1989). The Culicoides of Southeast Asia (Diptera; Ceratopogonidae). Mem. Amer. Ent. Inst. 44: 1 - 492.

Yanase, T., Kato, T., Kubo, T., Yoshida, K., Ohashi, S., and Yamakawa, M. (2005). Isolation of bovine arboviruses from Culicoides biting midges (Diptera: Ceratopogonidae) in southern Japan: 1985-2002. J Med Entomol, 42(1): 63-7. 